\title{
REVIEW
}

\section{Men's health in South Korea}

\author{
Sae-Chul Kim, Sang Wook Kim and Yun Jae Chung
}

Over the last four decades, rapid industrialisation and a Westernized lifestyle have changed disease patterns in South Korea. This study was conducted to review the current state of men's health in South Korea. By reviewing reports of government authorities and domestic and foreign studies related to men's health, we found that in men $\geqslant 65$ years of age, $28.4 \%$ considered their health status good, whereas $38.3 \%$ considered their health status poor. The prevalence of moderate-to-severe lower urinary tract symptoms was similar to that in Caucasians. The prevalence of erectile dysfunction was higher than the global average. The incidence of cryptorchidism and hypospadias showed a tendency towards increase. The prevalence of diabetes mellitus continuously increased by $10.8 \%$ in 2008 and was the fifth leading cause of death in 2008 . The prevalence of obesity increased from $26.0 \%$ in 1998 to $31.7 \%$ in 2007 . The prevalence of ischaemic heart disease has continuously increased, with heart diseases causing one of every 12 deaths. The prevalence of chronic obstructive pulmonary disease in 2005 was $17.2 \%$ among adults $\geqslant 45$ years of age. The top five prevalent cancers in men, in descending order, were cancers of the stomach, lung, liver, large bowel and prostate, among which the incidence of stomach, lung and liver cancers decreased by $0.7 \%, 0.6 \%$ and $2.2 \%$, respectively, from 1999 to 2007 , whereas the incidence of large bowel and prostate cancers increased by $7.0 \%$ and $13.2 \%$, respectively. The prevalence of depression, dementia and sleep disorders was estimated as $17.3 \%, 4.21 \%$ and $20.2 \%$, respectively. Together, these findings suggest that disease patterns in South Korean men are becoming Westernized.

Asian Journal of Andrology (2011) 13, 519-525; doi:10.1038/2010.134; published online 11 April 2011

Keywords: Health; men; South Korea

\section{INTRODUCTION}

The global increase in mean life expectancy and the drastic reduction in fertility rates have resulted in a rapidly ageing global population. South Korea is representative of such changes. The life expectancy in Korean men has been increasing, from 61.8 years in 1980 to 67.3 years in 1990, 72.3 years in 2000, 75.1 years in 2005 and 76.5 years in $2008 .^{1}$ The birth rate in South Korea is among the lowest in the world. The total fertility rate (1.47 in 2000, 1.08 in 2005 and 1.15 in 2009) and the growth rate of the population (1.57 in 1980, 0.99 in 1990, 0.84 in 2000 and 0.38 in 2004) have been declining. As a result, the national population is expected to peak in 2018 and to start declining thereafter. In contrast, the proportion of the population aged $\geqslant 65$ years has been continuously increasing, as shown by the following statistics: $3.82 \%$ in 1980 , $5.12 \%$ in $1990,7.2 \%$ in $2000,8.3 \%$ in 2005 and $9.9 \%$ in 2009 (Table 1). ${ }^{2}$

In addition to genetic determinants, environmental and lifestyle factors, including nutrition, exercise and substance use (i.e., smoking and alcohol abuse), also significantly affect the progression of ageing. According to the Third Korean National Health and Nutrition Examination Survey (KNHANES III) in 2005, the intake of cereals had been continuously decreasing from 1969 to 2005 (Figure 1a), whereas the intake of meat, milk and dairy products had been continuously increasing (Figure 1b), while vegetable intake showed no changes during this period (Figure 1a). ${ }^{3}$

Over the past four decades, rapid industrialisation, a Westernized lifestyle and the continuous increase in the ageing population have changed disease patterns in South Korea. The top three leading causes of death, malignant neoplasms, followed by cerebrovascular diseases and heart diseases, remained the same from 1998 to 2008. In 1998, the fourth and fifth leading causes of death were liver disease and traffic accidents; in 2003, they became liver disease and suicide, and in 2008, suicide and liver disease. ${ }^{4}$ South Korea spent $6.8 \%$ of its gross domestic product on health in 2009 . The spending per person has significantly grown over the past decade, although it remains lower than the Organization for Economic Cooperation and Development (OECD) average of $8.9 \% .^{5}$ In 2009 , the medical expenditures for the elderly $\geqslant 65$ years of age accounted for $31.4 \%$ of the total medical expenditures, a 1.6-fold increase, compared with that in 2002 (Table 1). ${ }^{2}$ This study was conducted to review the current status of men's health in South Korea.

\section{GENERAL HEALTH}

According to the 2008 Korean Statistical Information Service, ${ }^{6} 75.1 \%$ and $77.7 \%$ of Korean men regularly ate breakfast and maintained proper sleeping schedules $(6-8 \mathrm{~h})$, respectively. Of men $\geqslant 65$ years of age, $94.9 \%$ and $88.7 \%$ regularly ate breakfast and maintained proper sleeping schedules, respectively. In total, $35.1 \%$ and $44.4 \%$ of Korean men regularly exercised and received regular medical check-ups, respectively, whereas of men $\geqslant 65$ years of age, $39.2 \%$ and $64.7 \%$ regularly exercised and received regular medical check-ups, respectively. In comparison, of women $\geqslant 65$ years of age, $29.1 \%$ and $56.9 \%$ regularly

Department of Urology and Internal Medicine, Chung-Ang University College of Medicine, Seoul 156-755, Korea 
Table 1 Yearly trend of the proportions of the population and medical expenditures for individuals $\geqslant 65$ years of age $\mathrm{a}^{2}$

\begin{tabular}{lllllllll}
\hline Year & 2002 & 2003 & 2004 & 2005 & 2006 & 2007 & 2008 & 2009 \\
\hline $\begin{array}{c}\text { Population } \\
(\%)\end{array}$ & 7.2 & 7.5 & 7.9 & 8.3 & 8.6 & 9.2 & 9.6 & 9.9 \\
$\begin{array}{c}\text { Expenditure } \\
(\%)\end{array}$ & 19.3 & 21.2 & 22.8 & 24.4 & 25.9 & 28.2 & 29.9 & 31.4 \\
\hline
\end{tabular}

exercised (at least $30 \mathrm{~min}$ of exercise more than three times a week) and received regular medical check-ups, respectively. Ageing men were more concerned of their health than ageing women. Of men $\geqslant 20$ years of age, $50.8 \%$ were smokers, and $23.8 \%$ drank alcohol at least $3-4$ times a week, whereas of the elderly $\geqslant 65$ years of age, $15.6 \%$ and $22.7 \%$ were smokers and drank alcohol at least 3-4 times a week, respectively.

In the self-assessment of their health, rated on seven levels, $56.7 \%$ of men $\geqslant 15$ years of age rated their health as good, whereas $11.0 \%$ rated it as poor. Of men $\geqslant 65$ years of age, $28.4 \%$ rated their health as good, whereas $38.3 \%$ rated it as poor. The number of 'good' responders increased with increasing levels of education and income.

\section{GENITOURINARY SYSTEM}

\section{Benign prostatic hyperplasia (BPH) and lower urinary tract} symptoms (LUTS)

The incidence of LUTS increases with age, and the most common cause of LUTS in ageing men is BPH. Asian men have a smaller prostate than Caucasians. While the lifetime probability of surgical treatment in Americans at the age of 50 years has been estimated to be $25 \%-30 \%,{ }^{7}$ the probability of surgical treatment in Korean men at this age is only $4 \% .{ }^{8}$ However, reported data have shown that an enlarged prostate is not necessarily associated with the severity of LUTS $^{9}$ and that Asian men may have similar or higher symptom scores and a more impaired quality of life as compared with Europeans and Americans. ${ }^{10}$

In a community-based epidemiological study to determine the prevalence of LUTS in Korean men $\geqslant 50$ years of age, $23.3 \%$ were moderately to severely symptomatic $(17.7 \%$ in the 50 - to 59 -year age group, $23.3 \%$ in the 60 - to 69 -year age group and $35.3 \%$ in the $\geqslant 70$-year age group), suggesting that the prevalence of moderateto-severe LUTS in Korean men is similar to that in Caucasians. ${ }^{11}$ The proportion of severely symptomatic men approximately doubles with each decade of age. A previous study suggested that the higher
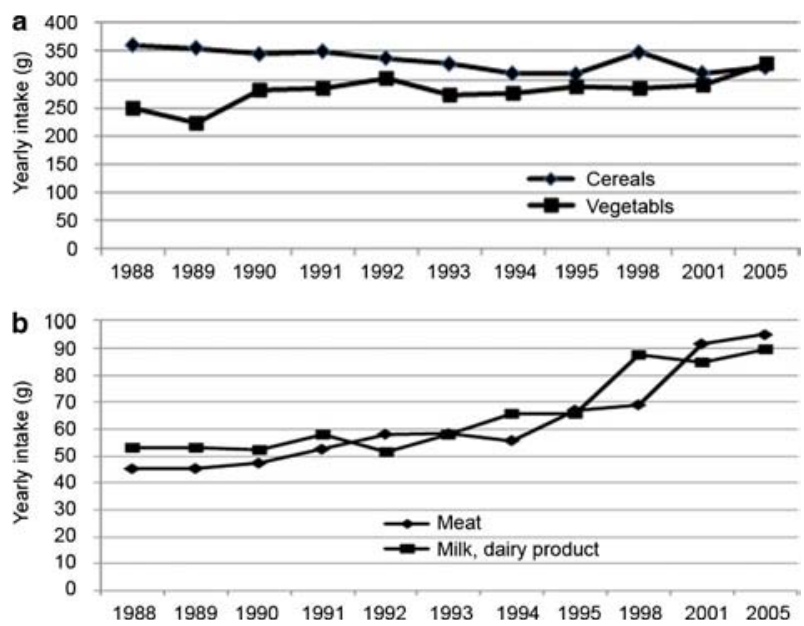

Figure 1 Yearly change in the intake of cereals and vegetables (a) and meat, milk and dairy products (b). Adapted with permission. ${ }^{3}$ ratio of the transition zone enlargement relative to the entire prostate in Korean men, compared with that in Caucasians, might be related to the higher incidence of clinical symptoms. ${ }^{12}$

Overactive bladder $(\mathrm{OAB})$ is a subset of storage LUTS defined as urgency, with or without urge urinary incontinence. The prevalence of $\mathrm{OAB}$ in Korean men was $29.9 \%$. OAB was more common in professional workers (43\%), high-income individuals $(26 \%)$ and urban dwellers $(64 \%)$. The incidence of OAB increased with age, and the prevalence was $53 \%$ in men $>70$ years of age. Urge incontinence symptoms were reported in $13 \%$ of men aged $\geqslant 18$ years. Some degree of suffering was recorded in $32 \%$ of men with $\mathrm{OAB}$, of whom only $5.9 \%$ received treatment for $\mathrm{OAB} .{ }^{13}$

Couples that have lived together for many decades share health concerns that directly affect their partners. This is particularly true in the cases of LUTS and clinical BPH because they occur in ageing men at a time when both partners are increasingly concerned about health matters and their vulnerabilities and susceptibilities to diseases. A study on LUTS in men on health-related quality of life of their spouses revealed that almost all spouses (98\%) suffered from one or more inconvenience to some degree ${ }^{14}$ (Figure 2).

\section{Erectile dysfunction (ED)}

The prevalence of ED is reported differently depending on the evaluation methods. Based on the fourth edition of the Diagnostic and Statistical Manual of Mental Disorders, the prevalences of ED in South Korea were $37.2 \%, 69.2 \%, 83.3 \%$ and $100 \%$ in men in their 50s, 60s, 70s and $>80$ years of age, respectively. ${ }^{15}$ In another survey using the International Index of Erectile Function, the prevalences of ED were $46 \%, 60 \%, 74 \%$ and $85 \%$ in men in their 30 s, 40 s, 50 s and $\geqslant 60$ years of age, respectively. ${ }^{16}$ The prevalences of self-reported ED, however, were much lower: $7.3 \%, 10.0 \%, 23.9 \%$ and $34.1 \%$ in men in their 40s, 50s, 60s and 70s, respectively. ${ }^{17}$ According to the Global Study of Sexual Attitudes and Behaviors, ${ }^{18,19}$ the prevalence of ED in Korean men aged $40-80$ years was higher than the global average and than that in other Asian regions. The higher prevalence of ED may be attributed to the relatively higher prevalence of risk factors for ED (Figure 3). However, only 2\% of men and women in South Korea discussed their sexual problems with a medical doctor. This low percentage was largely due to the belief that the problem is a natural phenomenon of ageing, the belief that the problem is not serious, not suffering from the problem, difficulties in accessing or in affording medical care, and/or the lack of awareness of available treatments. However, since the launch of Viagra, an improved understanding of $\mathrm{ED}$, an increased number of patients recognizing the need for treatment and the availability of convenient oral medication for treatment

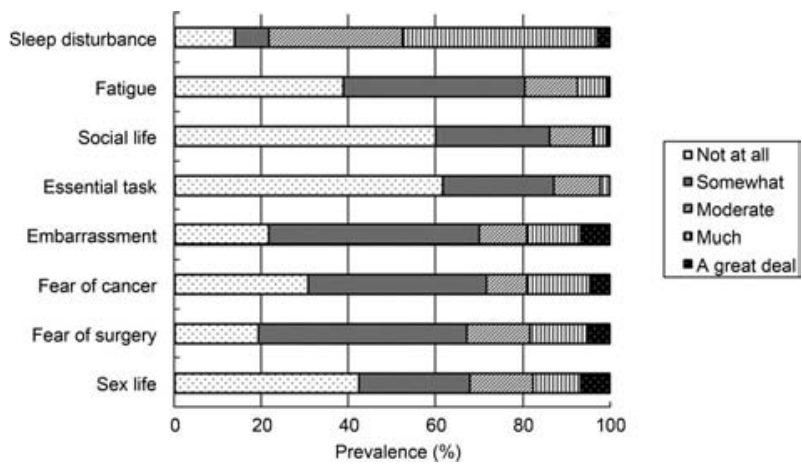

Figure 2 Prevalence of factors affecting partner's quality of life in men with lower urinary tract symptoms. Adapted with permission. ${ }^{14}$ 


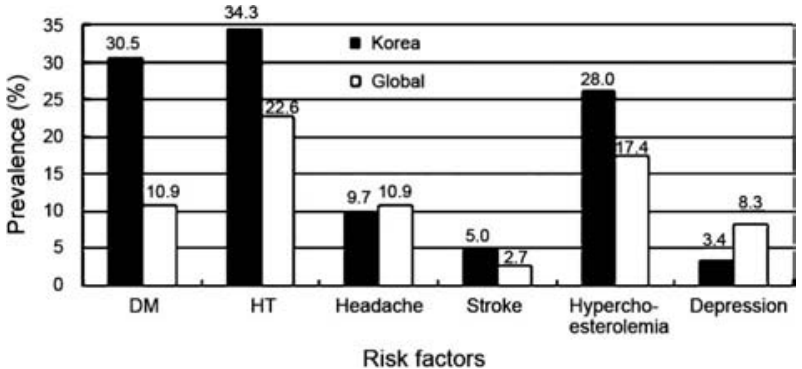

Figure 3 Prevalence of risk factors of erectile dysfunction: a comparison with global average. Adapted with permission. ${ }^{19} \mathrm{DM}$, diabetes mellitus; HT, hypertension.

have contributed to a significant increase in the number of patients visiting clinics for ED treatment. ${ }^{20}$

Not surprisingly, some illegal generic drugs are circulating on the black market, and this situation has led to drug misuse. A survey conducted in South Korea in 2008 revealed that $10.6 \%$ of men 20 60 years of age who purchased phosphodiesterase type 5 inhibitors bought the drugs without a prescription through non-pharmacy channels (acquaintance, Internet or sex shop) (75\%), pharmacy (13\%) and non-pharmacy/pharmacy $(12 \%) .{ }^{21}$ The oral agents purchased through non-pharmacy channels are presumably counterfeit.

\section{Infertility}

With the definition of infertility as the failure to conceive after 1 year of unprotected sexual intercourse, a study on the utilisation of health services and coping strategies for infertility conducted in South Korea in 2001 revealed that the rate of infertility in couples was $23.2 \%$ (primary, 10.8\%; secondary, $12.4 \%$ ). ${ }^{22}$ The rate of conception failure during the first year after marriage was $13.5 \%$, and it decreased to $11.3 \%$ ( $14.6 \%$ minus the $3.3 \%$ that were spontaneous abortions) after 3 years of marriage.

A male factor was identified as the cause of infertility in 30\%-40\% of couples and a contributing factor in $50 \%$ of the cases. ${ }^{23}$ Although no definitive nationwide data are available for the rate of male factor infertility in South Korea, among 920 new male patients who visited a hospital of infertility specialty for sterility from January 2009 to December 2009, 269 (29.2\%) were abnormal in $\geqslant 1$ parameter (count, motility and morphology) of sperm analysis, and 96 (10.4\%) were azoospermic. ${ }^{24}$ Of the men with abnormality in 1 parameter of the sperm analysis, $113(42.0 \%)$ presented with varicocele, whereas of 555 men diagnosed as normal in the sperm analysis, 84 (15.1\%) presented with varicocele. The causes of azoospermia were obstructive in $25.0 \%$ and non-obstructive in $70.8 \%$ (Table 2). The prevalence of Y-chromosome microdeletions in Korean men with infertility is $13.0 \%$ and $13.3 \%$ in patients with non-obstructive azoospermia and those with severe oligozoospermia, respectively. ${ }^{25}$

\section{Congenital anomalies, cryptorchidism and hypospadias}

A number of animal studies have shown that exposure to industrial chemicals containing estrogenic properties or anti-androgens in utero or during the perinatal period may cause cryptorchidism, hypospadias, reduced sperm count and testicular cancer in males, which may represent the symptoms of an underlying developmental disease, the testicular dysgenesis syndrome. ${ }^{26}$ Previously published studies have suggested that the incidence of these congenital anomalies has increased during the past half century in developed industrial countries, but not in less developed countries, ${ }^{26}$ and evidence suggests that
Table 2 Causes of azoospermia in Korean men. Adapted with permission $^{24}$

\begin{tabular}{ll}
\hline Cause & Number (\%) \\
\hline Obstruction & $24(25.0)$ \\
Vas/epididymis & 12 \\
Congenital vassal dysgenesis & 10 \\
Ejaculatory duct & 2 \\
Non-obstruction & $68(70.8)$ \\
Sertoli cell only syndrome & 33 \\
Maturation arrest & 10 \\
Hypospermatogenesis & 8 \\
Chromosomal abnormality & 17 \\
Retrograde ejaculation & $4(4.2)$ \\
Total & $96(100.0)$ \\
\hline
\end{tabular}

there is a geographical variation in the prevalence of cryptorchidism and hypospadias at birth. ${ }^{27}$

Industrial development has been remarkable over the past 40 years in South Korea, resulting in the spread of environmental pollution. ${ }^{28}$ In a recent study, the national incidence of cryptorchidism and hypospadias in males $0-4$ years of age increased from 5.01 to 17.43 per 10000 people and from 1.40 to 3.28 per 10000 people, respectively, between 2000 and $2005 .^{29}$

\section{ENDOCRINE SYSTEM}

\section{Diabetes mellitus (DM)}

Type $2 \mathrm{DM}$ is a major chronic disease and public health problem in South Korea. The prevalence of DM in South Korea increased from $<1 \%$ in 1960 to $6 \%-9 \%$ by the end of the 1990 s. $^{30,31}$ A recent largescale community cohort prospective study has shown that the genderand resident-specific annual incidence of type $2 \mathrm{DM}$ among people aged from 40 to 70 years rapidly increased (Table 3). ${ }^{32}$ The most recent report from the Fourth Korean National Health and Nutrition Examination Surveys (KNHANES IV) revealed that the prevalence of $\mathrm{DM}$ in the $\geqslant 30$-year age group was $10 \%$ (10.8\% in males and $9.3 \%$ in females). ${ }^{33}$ The rapid rise in the incidence and prevalence of DM in South Korea during the last decades may be attributed to an increased adoption of a Westernized diet, decreased physical activity, increasing obesity and a genetic background of susceptibility. ${ }^{34}$

A report by a task force assembled to study the epidemiology of Korean DM in 2003 reported the following results: 44.8\% of foot amputees were diabetic; diabetes affected $56.7 \%$ of all end-stage renal disease patients; and of those who underwent renal replacement therapy, $70.5 \%$ were diabetic. The incidence rates of cataracts, retinopathy and glaucoma were reported to be 3, 3.9 and 1.5 times more common in diabetics than those in non-diabetics, respectively. Acute stroke was estimated to be 5.2 times more common in diabetic patients compared with the general population. ${ }^{35} \mathrm{DM}$ was listed as the fifth leading cause of death in $2008 .^{36}$

Table 3 Gender- and resident-specific annual incidence of type 2 diabetes mellitus among people at $40-70$ years of age $\mathrm{e}^{32}$

\begin{tabular}{llllll}
\hline \multirow{2}{*}{ Age (year) } & \multicolumn{3}{c}{ Men } & & \multicolumn{2}{c}{ Women } \\
\cline { 2 - 3 } \cline { 5 - 6 } \cline { 5 - 6 } & Rural (\%) & Urban (\%) & & Rural (\%) & Urban (\%) \\
\hline $40-49$ & 1.68 & 2.35 & & 1.33 & 1.55 \\
$50-59$ & 1.65 & 3.18 & & 1.48 & 2.30 \\
$60-69$ & 1.85 & 4.55 & & 2.05 & 4.10 \\
$70-79$ & 3.93 & 5.00 & & 3.08 & 5.00 \\
\hline
\end{tabular}




\section{Thyroid diseases}

Thyroid diseases are common endocrine disorders and are much more prevalent in females than in males. Although there are no welldesigned, prospective cohort studies to evaluate the epidemiology of thyroid dysfunction in South Korea, the data from an institutionalbased, cross-sectional study showed a prevalence similar to that of other iodine-sufficient areas. ${ }^{37}$ The prevalence of hyperthyroidism, subclinical hyperthyroidism, overt hypothyroidism and subclinical hypothyroidism is shown in Table 4. The prevalence of hyperthyroidism and hypothyroidism peaked in the fifth decade and in the seventh decade, respectively.

\section{Obesity}

The prevalence of obesity is rapidly increasing in many countries, including South Korea. ${ }^{38-41}$ The data from KNHANES IV demonstrated that it ( $\geqslant 19$ years of age) dramatically increased from $26.0 \%$ in 1998 to $31.7 \%$ in $2007 .{ }^{33}$ The data showed a higher prevalence of obesity in males than in females since 1998 (Figure 4). The Westernized diet and a reduction in physical activity appear to have caused a rapid rise in the prevalence of obesity during the past 10 years. The prevalence of the metabolic syndrome has also markedly increased in South Korea recently. ${ }^{38,39}$

\section{CARDIOVASCULAR SYSTEM}

\section{Hypertension}

According to a Korean health survey, the prevalence of hypertension was $30.0 \%$ (32.4\% in men, $27.0 \%$ in women) in 1998 and decreased to $27.9 \%$ in 2005 (30.9\% in men; $24.1 \%$ in women) (Figure 5). Hypertension is more frequent in men, the elderly (the prevalence peaked in the 60s for men and in the 70s for women), people with low levels of formal education and people in a low income bracket. ${ }^{42}$ The overall mortality of hypertension was 10.4 per 100000 people (6.9 in men; 13.9 in women) in 2005. The yearly trend of mortality related to hypertensive diseases is shown in Figure 6. Strokes triggered by hypertension were one of the six leading causes of death in South Korea. $^{3,43}$

Hypertension accounted for 27.3 of 100000 deaths and contributed to nearly $70 \%$ of the mortality due to cardiovascular diseases. ${ }^{44}$ Age (in women), obesity (body mass index $>23 \mathrm{~kg} \mathrm{~m}^{-2}$ ), smoking $(>30$ pack-years; number of pack-years $=($ packs smoked per day $) \times($ years as a smoker) ), alcohol ( $>30$ g per day), lack of exercise, working $>40 \mathrm{~h}$ per week and insufficient sleep were suggested to be risk factors for hypertension. ${ }^{45}$ It has been suggested that Korean dietary habits (spicy and salty food and alcohol) may increase the prevalence of hypertension. ${ }^{46}$

Recently, a multicentre, nationwide, cross-sectional, populationbased survey involving 13184 hypertensive patients was conducted to investigate the current status of hypertension treatments in Korean patients. ${ }^{47}$ Based on the multivariate analysis, diabetes (odds ratio (OR): 5.57; 95\% CI: 5.05-6.13) and chronic kidney disease (OR:

Table 4 Prevalence of hyperthyroidism and hypothyroidism in men and women in South Korea (per 1000 people) ${ }^{37}$

\begin{tabular}{lrc}
\hline & Men & Women \\
\hline Hyperthyroidism & & \\
Overt & 3.6 & 7.7 \\
Subclinical & 11.8 & 13.0 \\
Hypothyroidism & & \\
Overt & 1.1 & 4.9 \\
Subclinical & 11.2 & 26.7 \\
\hline
\end{tabular}

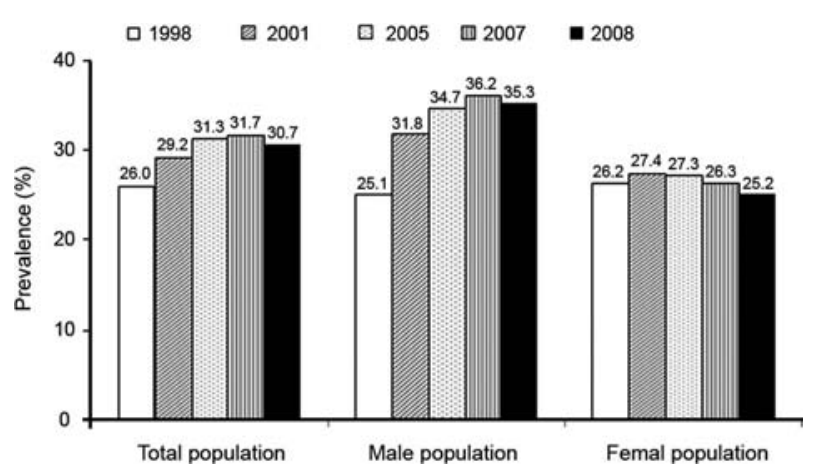

Figure 4 Age-related prevalence of obesity, defined as body mass index (BMI) $\geqslant 25 \mathrm{~kg} \mathrm{~m}^{-2}$. Adapted with permission. ${ }^{33}$

3.40; 95\% CI: 2.54-4.54) were the most significant independent factors related to poor blood pressure control.

\section{Coronary artery disease}

From 1983 to 2007, the prevalence of ischaemic heart disease had continuously increased, but it was somewhat decreased in 2008 (2\%). Ischaemic heart disease has become a leading cause of death in the $>50$-year age group. The overall mortality of ischaemic heart disease is 25.7 per 100000 people (27.8 in men; 23.6 in women). Heart disease caused one of every 12 deaths, and the total number of deaths due to ischaemic heart disease was 12760 in 2004. The prevalence of ischaemic heart disease was higher in men and in the elderly. Similarly, the mortality associated with ischaemic heart disease also increased in 2007 (Figure 7). ${ }^{43,48,49}$ The in-hospital case-fatality rate within 30 days of admission for acute myocardial infarction was significantly higher than the OECD average in 2007 (8.1\% versus 4.9\%), whereas in-hospital case-fatality rates for both ischaemic and hemorrhagic stroke were both lower than the OECD average $(2.4 \%$ versus $5.0 \%$ and $11.0 \%$ versus $19.8 \%$, respectively). ${ }^{50,51}$

Cardiovascular surgery was first introduced in South Korea in 1959, and the number of cases has increased annually. A total of 635 074 cardiovascular surgeries/interventions have been performed. While percutaneous coronary intervention using coronary stents has markedly increased during the past 10 years, bypass surgeries have not

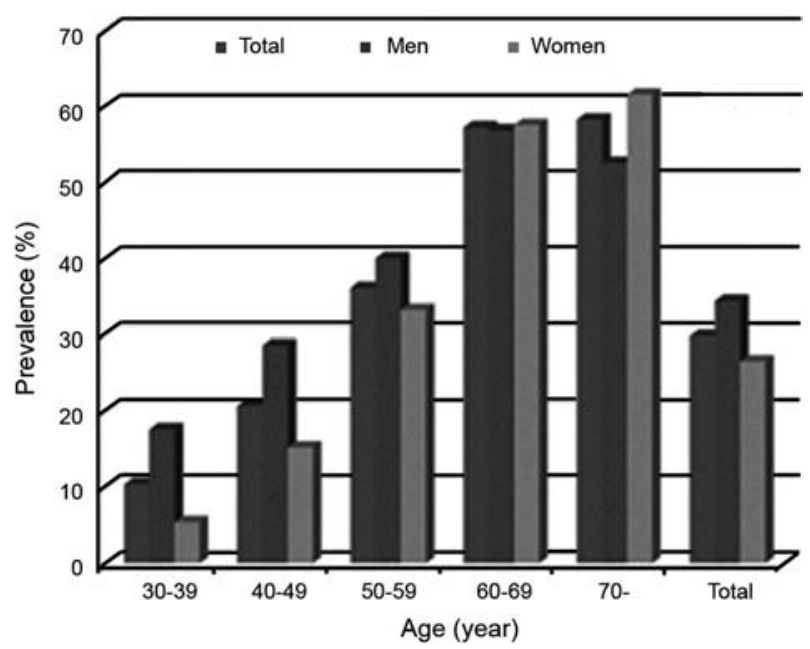

Figure 5 Prevalence of hypertension in accordance with age (\%). Adapted with permission. $^{42}$ 


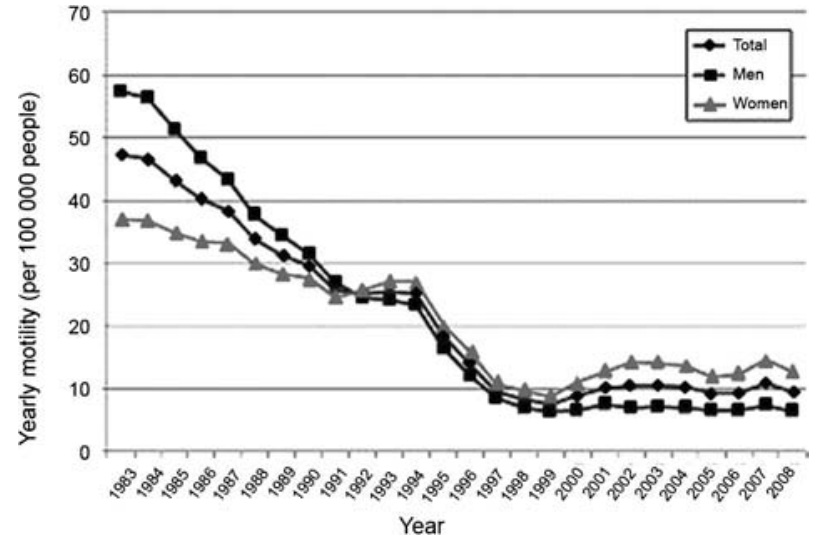

Figure 6 Yearly mortality related to hypertensive diseases (unit: per 100000 people). Adapted with permission. ${ }^{3,34}$

increased. ${ }^{52}$ Primary percutaneous coronary intervention is currently performed nationwide in patients with acute ST-elevation myocardial infarction; this progress may have a significant impact on decreasing the total mortality rate of acute myocardial infarction in South Korea. The use of statin therapy in patients with coronary artery disease has markedly increased and has improved the prognosis of these patients.

\section{CHRONIC OBSTRUCTIVE PULMONARY DISEASE (COPD)}

The exact worldwide prevalence of COPD is largely unknown, although it has been estimated to vary from $7 \%$ to $19 \% .{ }^{53}$ The prevalence of COPD in South Korea in 2005 was $17.2 \%$ among adults $\geqslant 45$ years of age. ${ }^{54}$ The primary cause of COPD is exposure to tobacco smoke. Although the role of air pollution in the aetiology of COPD is unclear, the effect is small compared with that of cigarette smoking. The proportion of non-smokers, men who quit smoking and current smokers among Korean men $\geqslant 45$ years of age accounted for $20.0 \%$, $26.8 \%$ and $53.2 \%$ of COPD cases, respectively. ${ }^{54}$ The prevalence of COPD was $14.6 \%$ in non-smokers, $27.8 \%$ in men who quit smoking and $28.6 \%$ in current smokers. The risk factors of COPD analysed by multivariate logistic regression were age (OR: 4.05; $P<0.0001$ ), male gender (OR: 2.62; $P<0.0001$ ), income (OR: $2.13 ; P<0.0001)$ and a $\geqslant 20$-pack-years smoking history (OR: $2.81 ; P<0.0001$ ).

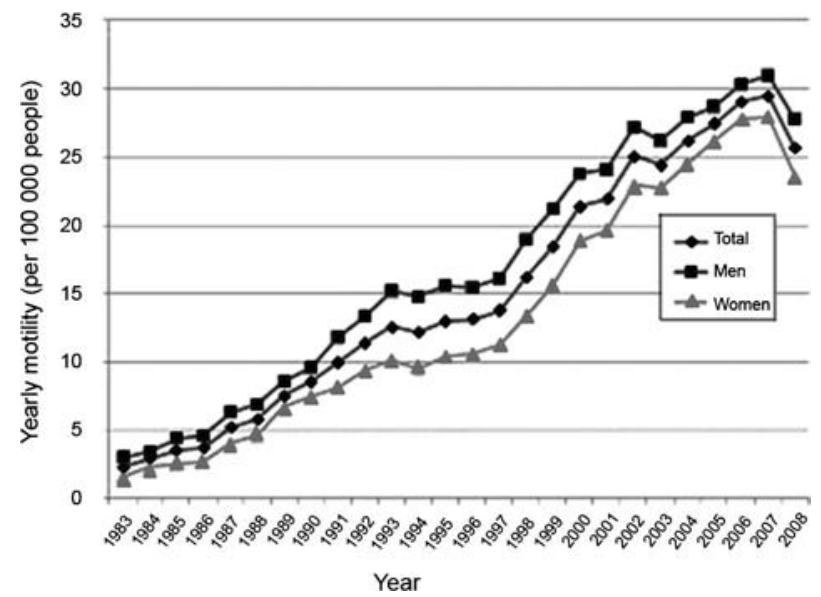

Figure 7 Yearly mortality related to ischaemic heart disease (unit: per 100000 people). Adapted with permission. ${ }^{43,48,49}$

\section{MALIGNANCY}

The epidemiology of cancer in South Korea has been changing in parallel with the increase in the number of elderly and the adoption of a Western lifestyle. The top five cancers in Korean men are cancers of the stomach, lung, liver, large bowel and prostate, ${ }^{5}$ among which the incidence of stomach, lung and liver cancers decreased by $0.7 \%, 0.6 \%$ and $2.2 \%$, respectively, from 1999 to 2007 , whereas the incidence of large bowel (7.0\%) and prostate cancers (13.2\%) increased during this period $^{55}$ (Figure 8). The incidence and mortality rates of stomach, liver and cervix cancers (known to be related to infections) have decreased, whereas the incidence rates of prostate, large bowel and breast cancers (so-called Western cancers) have increased, which may be attributed to the diet and lifestyles in South Korea that have been rapidly Westernized during the last 20 years. For colorectal cancer, the 5-year relative survival rate between 2001 and 2006 was close to the OECD average: $59.1 \%$ (OECD average, 56.4\%) for males and $57.1 \%$ (OECD average, $58.0 \%$ ) for females. ${ }^{5}$

Prostate cancer, the most rapidly increasing cancer in Korean men, has been one of the 10 most common cancers since 1996 and became the fifth most common cancer from 2003 to 2007. Prostate cancer accounted for $3.3 \%$ of all cancers during the same period, exceeding cervical cancer, which accounted for $2.2 \%$ of all cancers and was one of the five cancers included in the national cancer screening program. A report of the Korean Urological Association in 2009 demonstrated that the rate of detecting prostate cancer among men $\geqslant 55$ years of age was $3.4 \% .^{56}$ The 5 -year survival rate of prostate cancer in 2007 was $82.4 \%$, lower than that of breast cancer $(89.5 \%)$ and much lower than that of Americans with prostate cancer $(99.7 \%) .{ }^{55,57}$

Prostate cancer accounted for $0.5 \%$ of all deaths by cancer in Korean men in 1990, and the rate continuously and rapidly increased to $2.4 \%$ in 2008, becoming the seventh most common cause of cancer-related deaths. The blood level of prostate-specific antigen, a representative screening test for the early detection of prostate cancer, was introduced in South Korea in 1990 but was not widely adopted, therefore resulting in a continuous increase in yearly deaths caused by prostate cancer in

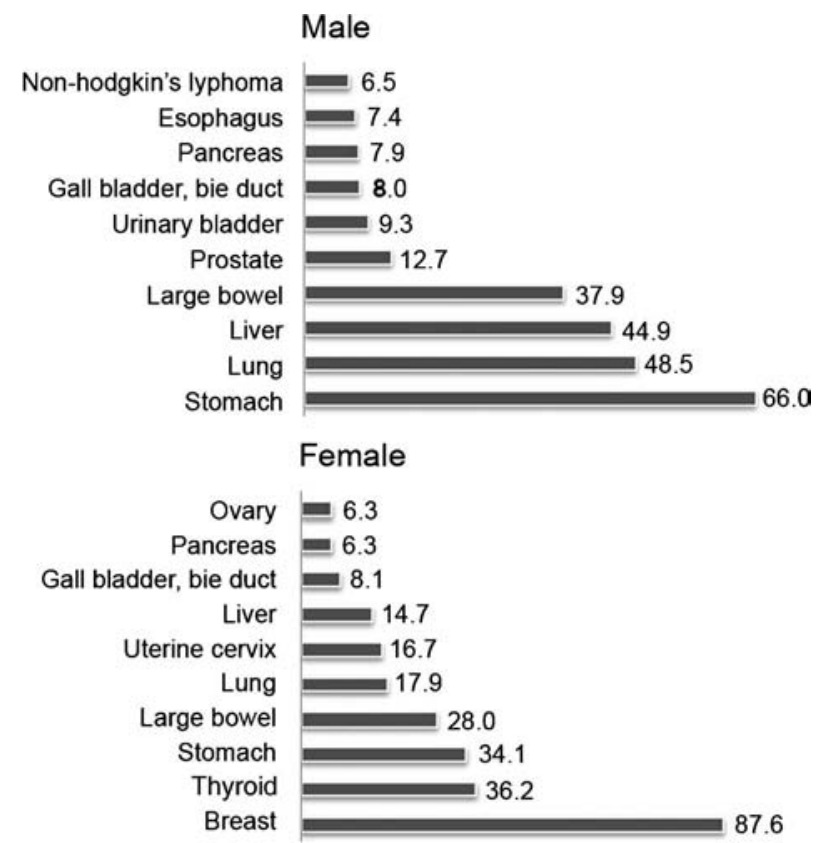

Figure $\mathbf{8}$ Incidence of 10 major cancers in South Korean in 2005 (unit: per 100 000 people). Adapted with permission. ${ }^{55}$ 
South Korea. In contrast, in the United States and United Kingdom, the prostate-specific antigen test was widely adopted when it was introduced, and the mortality of prostate cancer markedly decreased. ${ }^{58}$

The incidence of thyroid cancer has increased during the last two decades in South Korea. Thyroid cancer became the most common cancer in women and the sixth most common cancer in men in 2007. ${ }^{59}$ The age-adjusted incidence of thyroid cancer in 1986 was 3.9 in females and 0.8 in males per 100000 people per year. ${ }^{60}$ According to the data from the Korean National Cancer Registry, the ageadjusted incidence of thyroid cancer in 2007 was 64.8 in females and 11.6 in males per 100000 people per year. ${ }^{59}$ This dramatic increase in thyroid cancer incidence during the past 20 years appears to result from the improved diagnosis of small cancers due to the increased use of ultrasound-guided fine-needle aspiration biopsies in South Korea.

\section{MUSCULOSKELETAL}

The prevalences of musculoskeletal diseases were 144.6, 140.0 and 197.2 per 1000 people, and the annual self-reported prevalences of arthritis were 117.9, 109.2 and 146.4 per 1000 people in 1998, 2001 and 2005, respectively. Based on the KNHANES III, ${ }^{3}$ osteoarthritis was the most prevalent musculoskeletal disease in both genders, and $58 \%$ of persons $>65$ years of age presented with at least one musculoskeletal disease (73\% of women). The incidence of musculoskeletal diseases correlated with sociodemographic status.

\section{CENTRAL NERVOUS SYSTEM/PSYCHE}

\section{Cognitive impairment and depression}

The prevalence of cognitive impairment, based on a Korean MiniMental State Examination score $\leqslant 23$ and the prevalence of depression, demonstrated by a Centre for Epidemiologic Studies Depression score $\geqslant 25$, was estimated to be $18.8 \%$ (female, $47.0 \%$ ) and $17.3 \%$ (female, $17.9 \%$ ), respectively. ${ }^{61}$ The prevalence of depressive symptoms was not related to gender, age, year of education, marital status, physical illness, occupation, living condition or financial status. The prevalence of cognitive impairment (56.2\%) and depressive symptoms $(23.5 \%)$ in institutionalized elderly people was higher. ${ }^{62}$

\section{Dementia}

In a community study, the age-gender adjusted prevalence of dementia was $6.25 \%$ (male, $4.21 \%$; female, $8.28 \%$ ). The four statistically significant risk factors for dementia were age, illiteracy, unconsciousness after head injury and lack of exercise. ${ }^{63}$ In another study, the prevalence of dementia in an urban community was $7.0 \%$. Age and a low level of education were risk factors for dementia. ${ }^{64}$

\section{Sleep disorders}

In a nationwide survey involving 5000 men and women aged 21-69 years, the prevalence of sleep disorders was $22.8 \%$ (men, $20.2 \%$; women, $25.3 \%) .{ }^{65}$ The rate peaked in individuals in their $60 \mathrm{~s}$ (34.6\%) and was higher in those with lower incomes. Among those with sleep disorders, $8.6 \%$ experienced difficulties in falling asleep, and $11.2 \%$ experienced difficulties in staying asleep more than two nights per week.

\section{CONCLUSION}

A rapidly ageing population due to the increase in life expectancy and the drastic reduction in birth rates, a rapid industrialisation, Westernisation of the diet and a reduction in physical activity in South Korea has changed disease patterns in men, increasing the prevalence of BPH and LUTS, ED, congenital genitourinary anomalies such as cryptorchidism and hypospadias, DM, thyroid diseases, obesity, hypertension, coronary artery disease, COPD, colorectal and prostate cancers, and suicide. Consequently, a sharply rising medical expenditure for elderly men is becoming a real burden of national finance. Education regarding the value of preventive health care must be strongly encouraged at a national level to protect ageing men's health.

\section{COMPETING FINANCIAL INTERESTS}

The authors declare no competing financial interest.

1 Statistics Korea. Social indicators in Korea. Daejeon, Korea: Statistics Korea, October 2010.

2 Statistics Korea. 2009 key statistics of health insurance. Seoul, Korea: National Health Insurance Corporation, February 2010.

3 Statistics Korea. The 3rd Korea National Health and Nutrition Examination Survey (KNHANES III), 2005 - Nutrition Survey (1). Seoul, Korea: Korean Ministry of Health and Welfare, July 2007.

4 Statistics Korea. Annual report on the cause of death statistics. Daejeon, Korea: Statistics Korea, 2009.

5 Organization for Economic Co-operation and Development. OECD health at a glance 2009: key findings for Korea. http://www.oecd.org

6 Statistics Korea. 2008 Korean statistical information service. http://www.kosis.kr/ nsportal/eng

7 Glynn RJ, Campion EW, Bouchard GR, Silbert JE. The development of benign prostatic hyperplasia among volunteers in the Normative Aging Study. Am J Epidemiol 1985; 121: 78-90.

8 Lee E, Yoo KY, Kim Y, Shin Y, Lee C. Prevalence of lower urinary tract symptoms in Korean men in a community-based study. Eur Urol 1998; 33: 17-21.

9 Barry MJ, Cockett AT, Holtgrewe HL, McConnell JD, Sihelnik SA et al. Relationship of symptoms of prostatism to commonly used physiological and anatomical measures of the severity of benign prostatic hyperplasia. J Urol 1993; 150: 351-8.

10 Homma Y, Kawabe K, Tsukamoto T, Yamanaka H, Okada K et al. Epidemiologic survey of lower urinary tract symptoms in Asia and Australia using the international prostate symptom score. Int J Urol 1997; 4: 40-6.

11 Lee E, Yoo K, Kim Y, Shin Y, Lee C. Prevalence of lower urinary tract symptoms in Korean men in a community-based study. Eur Urol 1998; 33: 17-21.

12 Choi J, Ikeguchi EF, Lee SW, Choi HY, Te AE et al. Is the higher prevalence of benign prostatic hyperplasia related to lower urinary tract symptoms in Korean men due to a high transition zone index? Eur Urol 2002; 42: 7-11.

13 Moorthy P, Lapitan MC, Quek PL, Lim PH. Prevalence of overactive bladder in Asian men: an epidemiological survey. BJU Int 2004; 93: 528-31.

14 Kim SC, Lee SY. Men's lower urinary tract symptoms are also mental and physical sufferings for their spouses. J Korean Med Sci 2009; 24: 320-5.

15 Kim T, Chung TG, Ahn TY. Relation between urinary symptoms and erectile dysfunction: epidemiology study in Jeong-Eup, Korea. Korean J Androl 1998; 16: 87-91.

16 Ryu SB, Min K, Park K, Park Y, Rhee J et al. Epidemiologic study of the male erectile dysfunction with risk factors in rural area. Korean J Androl 2001; 19: 125-31.

17 Sohn H, Byun S, Park E, Cho KS, Jo MK et al. Prevalence of sexual dysfunction in men older than 40 living in Seoul; epidemiologic survey using questionnaire. Korean J Urol 2002; 43: 52-61.

18 Nicolosi A, Glasser DB, Kim SC, Marumo K, Laumann EO et al. Sexual behavior and dysfunction and help-seeking patterns in adults aged 40-80 years in the urban population of Asian countries. BJU Int 2005; 95: 609-14

19 Moreira ED Jr, Kim SC, Glasser D, Gingell C. Sexual activity, prevalence of sexual problems, and associated help-seeking patterns in men and women aged 40-80 years in Korea: data from the Global Study of Sexual Attitudes and Behaviors (GSSAB). J Sex Med 2006; 3: 201-11.

20 Kim SC, Park HS. Five years after the launch of Viagra in Korea: changes inperceptions of erectile dysfunction treatment by physicians, patients, and the patients' spouses. J Sex Med 2006; 3: 132-7.

21 Pfizer Korea, Hankook Research. Counterfeit market structure study. Seoul, Korea: Hankook Research, November 2008.

22 Korea Institute for Health and Social Affairs. A study on utilization of health services and coping strategies for infertility in Korea. Seoul, Korea: Korea Institute for Health and Social Affairs, January 2003.

23 Turek PJ. Male infertility. In: Tanagho EA, McAninch JW, editors. Smith's General Urology. New York: McGraw-Hill; 2008. pp684-716.

24 Seo JT. Personal communication. 2010.

25 Seo JT, Lee HS, Park YS, Jun JH, Yoon HS. Microdeletions of Y chromosome in infertile Korean men and correlation with pathologic presentation. Korean J Androl 2002; 20: 126-30.

26 Skakkebaek NE, Rajpert-De Meyts E, Main KM. Testicular dysgenesis syndrome: an increasingly common development disorder with environmental aspects. Hum Reprod 2001; 16: 972-8. 
27 Baskin LS. Hypospadias. Adv Exp Med Biol 2004; 545: 3-22.

28 Air Korea. Environmental Management Corporation - Ministry of Environment of Korea. http://www.airkorea.or.kr/

29 Kim SC, Kwon SK, Hong YP. Trends in the incidence of cryptorchidism and hypospadias of registry-based data in Korea: a comparison between industrialized areas of petrochemical estates and a nonindustrialized area. Asian J Androl; e-pub ahead of print 23 August 2010; doi:10.1038/aja.2010.53.

30 Park Y, Lee H, Koh CS, Min H, Yoo K et al. Prevalence of diabetes and IGT in Yonchon County, South Korea. Diabetes Care 1995; 18: 545-8.

31 Kim YI, Choi CS, Kim SW, Lee JS, Kim HH et al. Prevalence of diabetes mellitus and impaired glucose tolerance in Korean adults living in Jungup district, South Korea. J Korean Diabetes Assoc 1998; 22: 363-71.

32 Cho NH. Longitudinal epidemiologic study of diabetes mellitus: community cohor based genome project. National Institutes of Health: Bethesda, MD, USA, 2010 National Institutes of Health Annual Reports 2001-2009.

33 Korean Centers for Disease Control and Prevention. Korean National Health and Nutrition Examination Survey. http://knhanes.cdc.go.kr

34 Cho NH. Prevalence of diabetes and management status in Korean population. Korean J Med 2005; 68: 1-3.

35 Korean Diabetes Association and Health Insurance Review and Assessment Service. Report of Task Force Team for Basic Statistical Study of Korean Diabetes Mellitus. Diabetes in Korea 2007. 1st ed. Seoul: Goldfishery; 2008. pp30-8.

36 Statistics Korea. Annual report on the vital statistics 2008-2009. Seoul, Korea: Statistics Korea.

37 Chung JH, Kim BJ, Choi YH, Shin MH, Kim SH et al. Prevalence of thyrotoxicosis and hypothyroidism in the subjects for health check-up. J Korean Soc Endocrinol 1999; 14: 301-13.

38 Park HS, Lee SY, Kim SM, Han JH, Kim DJ. Prevalence of the metabolic syndrome among Korean adults according to the criteria of the International Diabetes Federation. Diabetes Care 2006; 29: 933-4.

39 Oh JY, Hong YS, Sung YA, Barrett-Connor E. Prevalence and factor analysis of metabolic syndrome in an urban Korean population. Diabetes Care 2004; 27 2027-32.

40 Flegal KM, Carroll MD, Ogden CL, Curtin LR. Prevalence and trends in obesity among US adults, 1999-2008. JAMA 2010; 303: 235-41.

41 Misra A, Khurana L. Obesity and the metabolic syndrome in developing countries. J Clin Endocrinol Metab 2008; 93: S9-30.

42 Korea Centers for Disease Control and Prevention. Chronic disease investigations. Seoul, Korea: Korea Centers for Disease Control and Prevention, 2001.

43 Korea Centers for Disease Control and Prevention. Health and chronic disease statistics. Seoul, Korea: Korea Centers for Disease Control and Prevention, 2005

$44 \mathrm{Kim} \mathrm{MK}$, Lee JY, Kim Y. Effects of alcohol consumption to blood lipids among Korean adults: the 2001 Korean National Health and Nutrition. Cancer Prev Res 2005; 10 : $173-9$

45 Lee HJ, Lee HS, Lee Y, Jang YA, Moon JJ et al. Nutritional environment influences hypertension in the middle-aged Korean adults: based on 1998 \& 2001 National Health and Nutrition Survey. Korean J Community Nutr 2007; 212: 272-83.
46 Kim YO. Dietary patterns associated with hypertension among Korean males. Nutr Res Pract 2009; 3: 162-6.

$47 \mathrm{Kim} \mathrm{KI}, \mathrm{Kim}$ Y, Kim HJ, Kang DH, Park JB et al. Current status and characteristics of hypertension treatment by primary physicians in Korea: data from Korean epidemiology study on hypertension (KEY study). Am J Hypertens 2008; 21: 884-9.

48 Korea Centers for Disease Control and Prevention. Public health nutrition investigations. Seoul, Korea: Korea Centers for Disease Control and Prevention, 2010.

49 Statistics Korea. Population investigations of social statistics. Daejeon, Korea: Statistics Korea, 2010.

50 Lloyd-Jones D, Adams RJ, Brown TM, Carnethon M, Dai S et al. Heart disease and stroke statistics 2010 update: a report from the American Heart Association. Circulation 2010; 121: e46-215.

51 Organization for Economic Co-operation and Development. OECD health at a glance. Paris, France: OECD, 2007

52 Korea Heart Foundation. Statistics, the annual report of cardiovascular surgery. Seoul Korea: Korea Heart Foundation, 2010.

53 Halbert RJ, Natoli JL, Gano A, Badamgarav E, Buist AS et al. Global burden of COPD. systematic review and meta-analysis. Eur Respir J 2006; 28: 523-32.

$54 \mathrm{Yu} \mathrm{JH}$, Kang KH, Shin DH, Kim YK, Lee KH et al. Guideline for management of chronic obstructive pulmonary disease of the Korean Academy of Tuberculosis and Respiratory Diseases. Seoul, Korea: The Korean Academy of Tuberculosis and Respiratory Diseases, November 2005.

55 Statistics Korea. The incidence of cancer statistics, 1999-2007. Daejeon, Korea: Statistics Korea.

56 Korean Urological Association. KUA report. Korean J Urol 2009; 50 (Suppl 1): XXIV.

57 National Cancer Institute. Surveillance Epidemiology and End Results (SEER) Program. Cancer statistics review. Bethesda, MD, USA: National Cancer Institute, 2010.

58 Park SK, Sakoda LC, Kang D, Chokkalingam AP, Lee E et al. Rising prostate cancer rates in South Korea. Prostate 2006; 66: 1285-91.

59 Korea Central Cancer Registry. Annual report of national cancer registry 2009. http:// www.ncc.re.kr.

60 Ahn YO, Park BJ, Yoo KY, Ahn HS, Kang DH et al. Incidence estimation of thyroid cancer among Koreans. J Korean Med Sci 1991; 6: 37-44.

61 Cho MJ, Hahm BJ, Jhoo JB, Bae JN, Kwon JS. Prevalence of cognitive impairment and depressive symptoms among the elderly in an urban community. Korean $J$ Neuropychiat 1998; 37: 352-62.

62 Cho MJ, Hahm BJ, Rhi BY, Kim SY, Shin YM et al. Prevalence of cognitive impairment and depressive symptomatology of the elderly in a long-term institution. Korean $J$ Neuropychiat 1998; 37: 913-20.

63 Park NH, Lee YM, Rie EL. Prevalence and risk factors of dementia in the community elderly. J Korean Acad Community Health Nurs 2008; 19: 36-45.

64 Hong SB. Prevalence of dementia in an urban community. Gimhae: MSc thesis, Inje University, 2007

65 Cho YW, Shin WC, Yun CH, Hong SB, Kim J et al. Epidemiology of insomnia in Korean adults: prevalence and associated factors. J Clin Neurol 2009; 5: 20-3. 